\title{
USO DE LAS FORMAS DE TRATAMIENTO EN CARTAS PRIVADAS ESCRITAS EN AMERICA EN EL SIGLO XVI (*)
}

\author{
Miguel Angel Quesada Pacheco
}

\begin{abstract}
An analysis of some private letters written by Spanish settlers in different parts of America during the XVIth century, in which each author describes the uses of the pronouns "vos", "vuestra merced" and "tú". The American "voseo" appears nowhere in those letters, which could mean that it doesn't take place until later, probably after the XVIIth century.
\end{abstract}

\section{INTRODUCCION}

A los lingüistas que se ocupan de la evolución de las formas de tratamiento en el español ha inquietado averiguar el uso de estas en la lengua coloquial. Así, en caso de que se tratara de estudiarlas en situaciones formales o en textos literarios, las fuentes son abundantes: las novelas, las obras de teatro y los documentos no oficiales del siglo XVI son afortunadamente cuantiosos y los estudios lingüísticos que las describen lo hacen en forma detallada y precisa (1). Sin embargo, si queremos analizar la forma en que los hablantes de español del siglo XVI - en nuestro caso, en las incipientes colonias americanas - se dirigían unos a otros en la vida cotidiana, el panorama se torna más difícil, pues no contamos con instrumentos que nos reflejen el trato diario, coloquial, de los primeros colonos americanos.

Con todo, una de las fuentes que mejor nos pueden ayudar a rellenar esa laguna son las cartas privadas escritas por inmigrantes a sus familiares en España, durante el siglo XVI, desde sus nuevos hogares en América. Y puesto que este tipo de documentación es igualmente escaso, las cartas descubiertas por el historiador colonial Dr. Enrique Otte (2) son un gran instrumento no solo para los historiadores - pues éstas narran aspectos de la vida diaria, penurias, alegrías y tristezas de los primeros pobladores de América - sino que, precisamente por estar escritas en un tono familiar, mu-

* El presente artículo se expuso en el Congreso de Lingüística y Literatura, Homenaje al Dr. Octavio Méndez Pereira, celebrado en Panamá del 4 al 10 de enero de 1988 chas veces fuera de influencias literarias o cancillerescas, son la fuente que más se acerca al uso cotidiano de la lengua $y$, por consiguiente, la que mejor nos puede reflejar el uso de las formas de tratamiento de la época, en situaciones informales, familiares y de solidaridad.

Movidos por el deseo de aportar algún conocimiento en este campo, y con la idea de contribuir al poco estudiado, pero ricamente documentado español colonial, hemos analizado algunas de las cartas privadas antes mencionadas. Con esto pretendemos, además, esbozar el uso informal de los pronombres de tratamiento en la América Colonial de la segunda mitad del siglo XVI y de principios del XVII y cotejar los resultados de la investigación con los de la bibliografía secundaria consultada al respecto.

\section{Estado de la cuestión}

Resumiendo la bibliografía consultada (3) sobre el uso de las formas de tratamiento en el español del siglo XVI, para la segunda persona singular, tenemos que:

a) los pronombres utilizados eran tú, vos y vuestra merced (que derivó en usted);

b) tú se usaba para dirigirse a una persona humilde, de rango social inferior; a iguales en situación de intimidad o de gran confianza; en estilos literarios tales como epistolas y oraciones; en hablas imaginadas y para hablar con niños;

c) vos (mas el verbo en segunda persona plural) se usaba entre iguales en situaciones formales; entre inferiores o superiores de manera respe- 
tuosa; para proferir ofensas a quien normalmente se tratara de $t u ́$; para dirigirse a siervos, campesinos o vasallos, y entre amigos en situaciones íntimas;

d) vuestra merced (más el verbo en tercera persona singular) era el tratamiento de respeto, formal, usado por personas de alto rango (pero no por la nobleza, que utilizaba vuestra señoría o vuestra excelencia) en situaciones de cortesía.

Se puede notar que, en el siglo XVI, se da una alternancia vos-tú sea en el plano de la solidaridad como en el de distanciamiento afectivo, a veces hasta en un mismo discurso (4). Luego, en el siglo XVII tú asume, en España, todas las funciones que tenía el pronombre vos, hasta hacerlo desaparecer (5).

Sin embargo, por influencia de la Corte, el uso de las formas de tratamiento comenzó a cambiar en América, en las regiones donde el contacto con la metrópoli era más fuerte: en los Virreinatos de México y del Perú, y en las Antillas, el pronombre $t u ́$, al igual que en la Península, desplaza al pronombre vos. Mientras tanto, en el resto del continente, donde los lazos comerciales y políticos con la corona española no eran tan fuertes, ocurre un proceso de mezcla pronominal de vos con $t u ́$, conocido con el nombre de voseo (6), cuya primera documentación, hasta la fecha, registra Lapesa en Bernal Díaz del Castillo, en 1520 (7).

La bibliografía consultada no permite entrever el uso de las personas gramaticales en situaciones de parentesco, que es el punto que nos ocupa. Con certeza porque, como se ha señalado, las investigaciones de esos autores se basan en documentos literarios o de carácter oficial.

\section{Emisor a receptor}

\section{Pronombre}

\section{Frecuencia (9)}

1. Padre a hijo

2. Tío a sobrino

3. Her. may. a her. menor

4. Hijo a padre

5. Sobrino a tío

6. Her. men. a her. may.

\section{Análisis de las cartas}

Los documentos analizados en este trabajo son cartas familiares, o privadas, escritas entre 1557 y 1616, por pobladores españoles residentes, en su mayor parte, en Puebla de los Angeles, México, pero también de pobladores de otras ciudades americanas como México, Panamá, Lima y Potosí. Se analizaron 50 cartas escritas por personas en la mayoría de los casos sin ningún cargo público elevado, sino, por el contrario, de oficios de clase media o inferior, tales como boticarios, tejedores, obrajeros, empleados públicos, agricultores, sastres y artesanos (8). No obstante, en la mayor parte de los documentos no se específica el cargo del emisor; lo cual es, a nuestro parecer, una prueba de la condición social inferior de quien envía la misiva. Muchos de estos pobladores tenían hasta 6 y más años de residir en las Indias.

Los destinatarios son familiares en España: padres de familia, esposas, hijos, hermanos, cuñados, sobrinos y primos. El fin de las cartas es informarles de lo que hacían, de como se hallaban, de la vida en el Nuevo Mundo y, en casi todas las cartas, se pide a sus seres queridos que hagan todo lo posible por embarcarse y hacerles compañía en la nueva vida. El tono familiar y coloquial, además de la redacción, dan a estos valiosos documentos una autenticidad difícil de encontrar en escritos de tipo literario u oficial; lo cual hace que se conviertan en un caudal de información lingüística incomparable, para intentar penetrar en el uso diario de la lengua española a principios de la Colonia.

El resultado del análisis de los pronombres usados en las cartas para dirigirse a los destinatarios se puede esquematizar de la siguiente forma: tú

vos

vuestra merced

vuestra merced

vuestra merced

vuestra merced

vuestra merced 


\section{Emisor a receptor}

7. Esposo a esposa

8. Hermano a hermano (no especifica edad)

9. Hermano a hermana

10. Hermana a hermano

11. Prima a primo

12. Primo a prima

13. Hombre a cuñado

14. Hombre a esposo de sobrina

\section{Pronombre}

vos

vuestra merced

alternancia vos/v.m.

vos

vuestra merced

alternancia vos/v.m.

vos

vuestra merced

alternativa vos/v.m.

vuestra merced

vos

vuestra merced

vos

vuestra merced

vuestra merced
Frecuencia (9)

8

1

3

1

6

1

3

3

1

1

1
Nótese que el pronombre vos del esquema no se refiere al voseo americano, sino al uso etimológico de vos más el verbo en segunda persona plural junto con el acusativo y el dativo vos y el posesivo vuestro.

En tres de las cartas analizadas se registró la alternancia vuestra merced/él o ella (según el sexo del destinatario) en forma ocasional. Por eso no se tomó tal alternancia como una constante en el esquema. Cabe acotar que, en el siglo XVI, el uso de él, ella estaba relegado a personas de condición rústica y sencilla y, entre personas que gozaban de una categoría social reconocida en la época como prestigiosa, el uso de tal pronombre era considerado "bajeza" o desdén y, con el tiempo, una afrenta (10).

En los grupos 1, 2 y 3 del esquema arriba expuesto, la relación de parentesco es descendente, es decir, de mayor a menor en la escala jerárquica familiar. En el grupo 1 los padres se dirigen a sus hijos con el pronombre tú, y son las únicas situaciones donde aparece tal pronombre. Este uso de tú calza con el que se registra en obras literarias desde la época del Poema de Mio Cid (11). Por otra parte, los grupos 2 y 3 indican que, en dos cartas analizadas, se usó vos y, en las otras dos, vuestra merced.
De acuerdo con la bibliografía a mano, vos tenía, en el siglo XVI, un uso ambiguo, pues denotaba tanto familiaridad como respeto, según la situación social. Por lo tanto, hemos de suponer que en esos casos el uso de vos está condicionado por las mismas situaciones sociales de carácter descendente en que se registra en obras literarias y oficiales de la época. En cuanto a uno de los dos casos donde se registra vuestra merced, el uno está sin duda condicionado por los oficios del emisor y del destinatario: el tío - el emisor - es empleado público y el destinatario - su sobrino - alguacil. Respecto del otro - hermano mayor a hermano menor - , su uso debe de responder, como se verá más adelante, a la generalización del uso de vuestra merced en las clases inferiores.

Los grupos 4, 5 y 6 se refieren a situaciones familiares de tipo ascedente: hijo a padre, sobrino a tío y hermanos menores a hermanos mayores. En todos se registra únicamente vuestra merced, que indica respeto. Por lo demás, el tratamiento de hijo a padre del grupo 4 contrasta con el del grupo 1 , donde el padre - que no es el mismo destinatario del grupo 4- trata de tú a su hijo. Esto es un fiel reflejo del tratamiento asimétrico, jerárquico, de poder, del cual nos hablan Brown y Gilman (12), 
atestiguado en varias lenguas europeas desde la Edad Media. Al respecto acotan:

"The individual's first experience of subordination to power and of the reverential V comes in his relation to his parents" (13).

Los grupos 7-12 denotan una relación simétrica, o sea, que penden de condiciones de similaridad: son cónyuges, tienen los mismos padres, provienen de un tronco familiar común. De las 30 cartas que se agrupan en esos casos, 13 registran el uso de vos, 12 vuestra merced y 5 alternan los dos pronombres. El hecho de que aparezca vos en cartas escritas por personas de rango social visto en el siglo XVI como inferior - sastres, tejedores, artesanos, etc. - es una prueba más de que tal ponombre, que en la Edad Media era el signo de distinción de los que ostentaban un rango social considerado superior, se había generalizado en forma vertical, hasta llegar a usarse por todos los individuos de la sociedad (13). Respecto del uso de vuestra merced, que para el siglo XVI llegó a denotar respeto, cortesía y distanciamiento afectivo en forma general, en las cartas analizadas aparece para dirigirse a cónyuges, hermanos y primos, es decir, para interlocutores dentro del plano de la solidaridad.

Si tomamos en cuenta la época en que las cartas fueron escritas - segunda mitad del siglo XVIhemos de concluir anotando que, ya para esos años, y en un período relativamente corto, el pronombre vuestra merced, el cual, según Pla Cárceles, para el primer tercio del siglo XVI "se generalizó como tratamiento cortesano aplicable a personas principales" (14), sufrió exactamente el mismo proceso de generalización a que se vió sometido el pronombre vos en la época medieval, no sólo en forma descendente, sino también desde el plano del distanciamiento al plano de la solidaridad. En este sentido, las cartas estudiadas son, hasta donde tenemos conocimiento, las primeras muestras del uso de vuestra merced en el plano de la solidaridad. Prueba de ello son las cinco cartas restantes, en las que el emisor alterna vos-vuestra merced, dándole al último el mismo valor que a la sazón tenía vos.

Por último están los grupos 13 y 14, los cuales tienen la característica de que los emisores guardan relaciones de parentesco político: excepto uno, todos son cuñados. Y también, excepto uno, todos los emisores se valen del pronombre vuestra merced para dirigirse a sus interlocutores. En estas situaciones, podríamos interpretar el uso de esta forma pronominal como una neutralización, es decir, que vale tanto para indicar distanciamiento como para solidaridad. Esto porque carecemos de datos que nos permitan corroborar el grado de amistad existente entre emisores y receptores, y teniendo en mente que tal pronombre también está registrado en casos de familiaridad, como hemos visto anteriormente.

\section{Logros obtenidos y conclusiones}

El análisis de las formas pronominales en algunas cartas privadas de la segunda mitad del siglo XVI y principios del XVII nos permiten llegar a las siguientes observaciones:

1. Queda demostrado el uso del pronombre vuestra merced en el plano de la solidaridad y en grupos de rangos sociales considerados medios o inferiores. Tomando en cuenta que vuestra merced evolucionó a usted en el siglo XVII, con certeza son estas atestiguaciones la gestación del uso de usted en la actualidad, en varias regiones americanas - como es el caso de Costa Rica (16) - , con el valor de solidaridad y confianza, usado entre cónyuges, hermanos, primos y amigos. Además, podría interpretarse la alta frecuencia del uso de vuestra merced como producto de la "hidalguización" del inmigrante español en colonias americanas, de que nos habla Rosenblat (17).

Cabe agregar que no se registró ningún caso del pronombre usted, ni de pruebas que atestigüen el uso único y general de ustedes para la segunda persona plural en el español americano actual. En otras palabras, se registraron usos de vosotros alternando con vos para esa persona.

2. El uso de las formas pronominales en cartas escritas en México y Lima revela que el uso de $t u ́$ como marcador de solidaridad no se había establecido, al menos a nivel de la muestra estudiada, en las clases consideradas inferiores. El uso de este pronombre en las cartas indica únicamente poder; es decir, la relación mayor-menor.

3. A diferencia de vos/vuestra merced, no se registraron alternancias del tipo tú/vos o tú/vuestra merced. Esto podría reflejar, por una parte, que todavía no se daba la coexistencia vos-tú en el plano de la solidaridad (a menos que los emisores no tuvieran bastante confianza con los destinatarios, lo cual nos parece inconcebible, por lo menos en los casos de relación 
familiar íntima). Por otra parte, es una indicación más de que todavía no estaban dadas las condiciones para el surgimiento del voseo americano.

Lo anterior nos incita a afirmar, a manera de hipótesis, que la coexistencia vos/tú, que dio origen al voseo, no se dio en América en el siglo XVI, o sea, en los primeros años de la época colonial, sino lenta y gradualmente, como producto de la extensión semántico-social de tú y de su intromisión en el paradigma pronominal de vos. De hecho, en las primeras documentaciones de voseo que hemos hallado para Costa Rica (18), se registra la alternanccia de los posesivos vuestro/tu ya entrado el siglo XVIII.

Estando así las cosas, la primera muestra de voseo atestiguada en América (ver nota 7) y las alternancias en los paradigmas correspondientes a vos y a tú que se dieron en la época medieval (en Lapesa, Las formas verbales..., p. 520 y ss.) se podrían catalogar como "pre-historia" del voseo americano.

No obstante, si mantenemos la distinción entre voseo pronominal y verbal (19), deberemos anotar que, respecto de las formas verbales de segunda persona plural registradas en las cartas, sí se registraron, aunque ocasionalmente, terminaciones monoptongadas que se utilizan en la actualidad en el voseo: darés (México 1571) recebistes (Puebla 1575), tengás (Atrisco 1581), etc., además de las formas imperativas sin la /-d/ final: procurá, enbiame (México 1574), escrevime (Puebla 1576), etc.

Para concluir, es importane dejar claro que, desafortunamente, no contamos con las respuestas de los destinatarios a las cartas enviadas desde América por sus familiares; documentación que nos podría ayudar a detectar si el tratamiento era o no simétrico. Además, faltan cartas que hayan sido escritas en otras latitudes del continente americano, para averiguar si había, desde ese tiempo, diferencias regionales en las formas de tratamiento, o bien, para ensanchar y complementar nuestros conocimientos al respecto (20). Pero esto será tarea que se deberá emprender con la ayuda de las innumerables fuentes con que contamos, tanto en los archivos americanos como en los españoles, y con un poco más de interés, por parte de los lingüistas, por revelar la gestación del español en América.

\section{NOTAS BIBLIOGRAFICAS}

(1) Cfr. por ejemplo:

Brown y Gilman: "The Pronouns of Power and Solidarity". En: J. Fishman (editor), Readings in the Sociology of Language, 3a. ed., La Haya-Paris 1972, p. 252-275; J. Pla Cárceles: "La evolución del tratamiento de "Vuestra Merced'”. En: RFE, X (1923); 245-280;

Rafael Lapesa: "Personas gramaticales y tratamientos en español". En: Rev. de la U. de Madrid. Homenaje a Menéndez Pidal, IV. Madrid 1970, Vol. XIX, No. 74; 141167 ;

Charles Kany: American-Spanish Syntax. Univ. of Chicago 1975 , p. 56 y ss.

Hayward Keniston, The Syntax of Castilian Prose: The sixteenth Century. Chicago 1937, p. 42 y ss.

(2) Se trata de 688 cartas existentes en el Archivo General de Indias, en Sevilla, algunas de las cuales se han publicado en la revista Jahrbuch fuer Geschichte von Staat, Wirtshchaft und Gesellschaft Lateinamerikas, Vol. 3 (1966); p. 10-87 y Vol. 6 (1969): p. 1-40 y forman el corpus del presente análisis.

(3) Ver nota 1.

(4) Cfr. R. Lapesa, op. cit., p. 519.

(5) Los últimos casos de vos los registra Pla Cárceles, para España, en el siglo XVIII.

(6) Cfr. Ch. Kany, op. cit., p. 56; p. 58 y ss.; R. Lapesa: "Las formas verbales de segunda persona y los orígenes del "voseo"'. En: Actas del III Congreso Internacional de Hipanistas (México 1968). México 1970; p. 519-531).

(7) Es el famoso façételo vos (R. Lapesa, Las formas verbales..., p. 522).

(8) Cfr. C. Meléndez, Conquistadores y pobladores de Costa Rica, San José 1980, p. 105, donde se da un cuadro esquemático de las clases sociales, rangos y cargos u oficios en la Colonia durante el siglo XVI, la cual ha servido de base para la clasificación de rangos y oficios en el presente estudio.

(9) La frecuencia se refiere al número de cartas en que aparece la forma pronominal en cuestión.

(10) Cfr. R. Lapesa, Personas gramaticales..., p. 158 y ss.

(11) Cfr. Ch, Kany, op. cit., p. 58.

(12) Op. cit., p. 259 (oposición padre-hijo).

(13) Brown y Gilman, op. cit., p. 255.

(14) Cfr. R. Lapesa, Personas gramaticales..., p. 145 y s.

(15) Op. cit., p. 245. 
(16) Cfr. C. Vargas: "El uso de los pronombres 'vos' y 'usted' de Costa Rica". En: Revista de Ciencias Sociales, VIII (1975), p. 7-30;

Ch. Kany, op. cit., p. 93 y ss.

(17) A. Rosenblat: "Base del español de América: Nivel social y cultural de los conquistadores y pobladores". En: Boletín de Filología, Santiago, XVI (1964); p. 214 y ss.

(18) Las primeras documentaciones de voseo en Costa Rica las hallamos en un documento escrito en Cartago en 1723 (Miguel A. Quesada Pacheco, Fuentes documentales para el estudio del español colonial de Costa Rica, San José 1987: Archivo Nacional, Sección Colonial, Serie Complementario, No. 4136) y en la misma ciudad, en 1725 (Archivo Eclesiástico de la Curia Metropolitana: Documentación Histórica, caja 12, libro 15 , folio 49 ). Es de observar que no hallamos ninguna documentación de voseo americano en Nicolás Castillo: "Testimonios del uso de 'vuestra merced', 'vos' y 'tú' en América (1500-1650)". En: Thesaurus, XXXVII, No. 1; p. 602644.

(19) Cfr. M. Fontanella: "La constitución del paradigma pronominal de voseo". En: Thesaurus, XXXII (1977); p. 227 y ss., donde distingue el pronombre vos - voseo pronominal - de la forma verbal que lo acompaña, denominado voseo verbal.

(20) En conversación telefónica (marzo de 1984) con el Dr Enrique Otte, descubridor de las cartas que aquí analizamos, me informó que descubrió cartas de todos los países centroamericanos, menos de Costa Rica. Esto, que no deja de ser una limitación para el estudio de las formas pronominales en este país durante sus primeros años coloniales, es sin duda producto de su colonización tardía y de su marginación respecto de otras colonias centroamericanas. 